\title{
TRANSFORMAÇÕES DA CHINA NARRADAS PELA LITERATURA EM LÍNGUA PORTUGUESA
}

\section{CHINA'S CHANGES TOLD BY LITERATURE IN PORTUGUESE LANGUAGE}

\author{
Sérgio Pereira Antunes*
}

Resumo: Desde o final do século XIX, a China vem passando por marcantes transformações econômicas, culturais, sociais, enfim transformações de todos os tipos. Neste mundo globalizado, as notícias a esse respeito chegam ao Ocidente e, em especial, ao Brasil, sempre intermediadas pelos grandes e poderosos grupos da mídia mundial. A literatura em língua portuguesa, por sua vez, com toque próprio da latinidade, em diferentes momentos históricos destes últimos 110 anos, nos apresenta essas transformações em relatos interessantíssimos de Wenceslau de Moraes, Ligia Fagundes Telles, Henfil, João Alves entre outros. As transformações da China podem, portanto, ser aprendidas por testemunhos oculares e com delicioso toque literário.

Palavras-chave: China. História. Revolução. Cultura. Literatura.

\begin{abstract}
Since the late XIX century, China has experienced remarkable economic, cultural, social, and all sort of transformations. In a globalized world, the news about such transformation reaches West and especially Brazil, always intermediated by large and powerful worldwide media groups. In different historical moments during the past 110 years, the literature in Portuguese language, in turn, with a proper touch of Latinity, has presented us such transformations by means of very interesting reports written by Wenceslau de Moraes, Ligia Fagundes Telles, Henfil, João Alves and others. Therefore transformations in China can be learned through eyewitness reports with delicious literary touch.
\end{abstract}

Keywords: China. History. Revolution. Culture. Literature.

A China vem passando por transformações importantes. Isso ninguém pode negar, eis que somos bombardeados diariamente por notícias que chegam do Oriente em um flash neste mundo globalizado e moderno. São transformações de todos os tipos: econômicas, culturais, sociais, tecnológicas etc.

Nem sempre foi assim. Houve tempos em que a forma epistolar era então o meio próprio para se ter notícias, pois, nem o telégrafo, após sua invenção em meados do século XIX, poderia

\footnotetext{
* Sérgio Pereira Antunes - Pesquisador do LIA Laboratório de Interlocuções com a Ásia, da Faculdade de Filosofia Letras e Ciências Humanas da Universidade de São Paulo. Email: <santunes@usp.br>.
} 
dar conta da divulgação, eis que não existia uma rede de cabos submarinos adequada. Houve também tempos de Guerra Fria, quando notícias do lado comunista do mundo só chegavam à grande mídia se atendessem interesses ocidentais. Os grandes grupos noticiosos internacionais, com exceção de alguns mais liberais, lidavam com o seu trabalho de divulgação de alguma forma cumprindo o determinado por políticas públicas nacionais e outras internacionais.

Na segunda metade do século XIX, o turismo e seu instigante interesse por conhecer outras paragens, aliados à invenção da fotografia, criaram um ambiente propício, no Ocidente, para se querer saber mais sobre mundos distantes como a China.

Na segunda metade do século XIX, o gênero literário das narrativas de viagem se popularizou bastante, em especial, na Europa e

consistia, principalmente, no registro do escritor acerca de um lugar, privilegiando fatos ou instantâneos que melhor se amoldassem ao seu interesse narrativo. Na maioria das vezes, os textos resultam de laboriosa pesquisa e revelam a preocupação com o que já tinha sido dito e com o destinatário, mesmo quando existe a afirmação que não se pretendia publicá-los ${ }^{1}$.

Alheia a questões políticas e tecnológicas, sob a forma de narrativas de viagem, boa literatura foi escrita e perenizou fatos históricos, modos de vida, culturas e eventos sociais dos mais diversos, que jamais seriam revistos ou relidos caso fossem apenas reportagens midiáticas, eis que estas são por demais fugazes.

É por meio dessas narrativas de viagem, de reconhecida beleza literária, que temos hoje registradas observações e testemunhos oculares das transformações da China por mais de um século.

Claro está que essas narrativas poderiam estar eivadas de exotismo, egotismo e até de um orientalismo negativo de que fala Said, eis que evocavam e reportavam os costumes, as gentes e as paisagens de um país exótico pouco conhecido pelas grandes massas ocidentais, ou porque se utilizava de um método literário em que o próprio eu é o ponto de referência de investigações e experimentos psicológicos ou, ainda, por reportar o Oriente pelo olhar distorcido ocidental.

Dentre esse estilo de narrativas que se perpetuou pelos anos vindouros do século $\mathrm{XX}$, em língua portuguesa, podemos pinçar: Traços do Extremo Oriente, de Wenceslau de Moraes com relatos de 1885-1895, Passaporte para China: crônicas de viagem, de Lygia Fagundes Telles, escrito em 1960, China: uma nova civilização, de Raimundo Pimentel Gomes,

\footnotetext{
${ }^{1}$ DUARTE, 1999, p. 61.
} 
publicado em 1962, Henfil na China: antes da Coca-Cola, escrito por Henfil e publicado em 1980, No outro lado do mundo: uma viagem para aprender, de João Alves Filho, publicado nos anos de 1980, Viajando pelos Cinco Continentes de José Cretella Jr. com duas edições sendo a última em 2001, além das narrativas indiretas ou imaginativas como $O$ Mandarim de Eça de Queiroz. Todas com grande utilidade para história, sociologia, antropologia etc., viabilizando interessante panorâmica e compreensão das transformações pelas quais a China passou.

\section{Traços do Extremo Oriente, de Wenceslau de Moraes}

Em 1895, Wenceslau de Moraes publicou seu primeiro livro, Traços do Extremo Oriente, trazendo informações preciosíssimas sobre a China e, também, a respeito do Japão e, ainda, das relações deste com a China. Embora Wenceslau de Moraes seja hoje reconhecido como o grande expoente na revelação do Japão para o mundo lusófono, este seu primeiro livro (como também uma coletânea posterior que o complementa, Paisagens da China e do Japão) apresenta ao Ocidente uma China por meio de uma narrativa determinada pelo contexto próprio do final do Século XIX. Moraes, como oficial da Marinha portuguesa, estava empenhado nas políticas públicas daquela Força Armada que se modernizou e cumpria a missão de ser o braço avançado das relações exteriores e da diplomacia de Portugal, fazendo de suas colônias um grande Brasil.

Em Macau, Wenceslau de Moraes assumira o cargo de Imediato do Porto de Macau, estabeleceu seu domicílio e constituiu família. A ociosidade do cargo, as passagens pela

China e umas poucas viagens ao Japão foram importante motor para construção de sua primeira obra publicada. Construída ao gênero das narrativas de viagem, sua escrita acerca da China é bastante naturalista, enquanto os relatos do Japão e de suas musumés já têm cadência para uma narrativa mais impressionista.

Traços do Extremo Oriente revela quase 10 anos de vivência na China de um escritor que quer reportar aos seus conterrâneos as novidades que correm por aquelas paisagens tão exóticas. Os anos 1885 a 1895 estão ali bem retratados e registrados para a compreensão do Oriente e do universo chinês.

Por essa obra, compreende-se a triste situação da China, num período de fragilidade imposta pelas nações imperialistas ocidentais, por meio de Tratados de Comércio e Amizade, 
que de parceria amistosa nada tinham, ao contrário, apenas predispunham direitos comerciais nada favoráveis à China. Na obra, restam, também, evidenciadas as falácias que culminaram com a guerra Sino Japonesa de 1895, além de trazer a tradução para o português da panfletagem japonesa, em que o Imperador do País do Sol Nascente encorajava seu povo a uma luta contra a China por motivos torpes, um verdadeiro documento histórico inserido num livro de grande beleza literária.

No final do século XIX, o cenário era nada favorável ao engrandecimento da China. Ao contrário, o grande Império Celeste já dava sinais de desmoronamento. A República surgiria, em breve, tanto em Portugal, em 1910, como na China, em 1911. Em Macau, Wenceslau conviveu com Sun Yetsen, o grande mentor da Revolução Republicana Chinesa.

Em que pesem as mazelas, ainda assim, Wenceslau conseguiu apresentar o universo chinês, suas lendas, sua cultura e seu modo de vida, destacando belezas, em especial em Macau, e, por vezes, tristezas - contrapontos necessários para a compreensão das transformações daquele período na China e na ordem econômica oriental.

\section{Passaporte para China: crônicas de viagem de Lygia Fagundes Telles}

A obra Passaporte para China é a coletânea de 29 crônicas de Lygia Fagundes Telles escritas para o jornal Última Hora produzidas quando de sua viagem à China em 1960, atendendo convite do governo chinês que comemorava 11 anos de fundação da República Popular da China.

Lygia chegou a Pequim em 29 de setembro de 1960 e reportou a Nova China que tinha apenas 11 anos de idade saída de uma velha China de cinco mil anos, "pátria dos antigos sábios e mandarins de roupa dourada e palácios de jade"2. Pela sua narrativa, fica claro que estava curiosa em ver como ficara aquela civilização milenar, sua dourada sabedoria e a persistente miséria. Entretanto por estar cumprindo uma visita oficial não the foi possível explorar em demasiado. Perguntou muito e aprendeu muito bem os motes que embasavam o padrão organizacional da Nova China e a inquestionável disciplina do povo, afinal "a Cidade Proibida está realmente aberta para as novas gerações que gostam de ouvir e ler a frase da Nova China: 'o céu é para todos'”3.

\footnotetext{
2 TELLES, 2011, p. 46.

${ }^{3}$ TELLES, 2011, p. 54.
} 
Aprendeu que os chineses não são nem superiores nem inferiores aos outros povos, são apenas diferentes. Observar tais diferenças foi uma constante de sua narrativa. Da língua, aprendeu que "obrigado" é "cêcê" (deveria ser xie, xie), que "Pequim" (Beijing) é a capital do norte.

Do que sabia sobre a China - uma população demasiado densa para um país demasiado pobre - aprendeu, na conferência de Mao Tse Tung, que "é preciso que o futuro saia do próprio passado". Assim, viu transformações e fez descobertas, enriquecendo sua narrativa com passagens interessantes e de grande beleza literária.

\section{Henfil na China antes da Coca-Cola}

Henfil na China antes da Coca-Cola reporta a viagem que o autor empreendeu, em 1977, por querer sentir fortes emoções, surpresas visuais, cultura regional, tudo isso longe das cidades que têm a mesma cara. A narrativa é alegre, por consequência, agradável e a percepção de transformações e da verdadeira China são surpreendentes.

As preocupações iniciais, reportadas por Henfil nesta sua obra, evidenciam, de pronto, transformações incontestes da China e, também, da visão externa que se tinha daquele país:

como não sou comunista, os chineses poderiam não me deixar entrar. ...eu estava crente que seria uma viagem assim bem clandestina ... Pois tive a maior decepção quando soube que a China Comunista tem embaixada no Brasil e, em Brasília, se tira visto de entrada. ${ }^{4}$

Henfil reporta com detalhes cada uma de suas descobertas, explica-as, justifica-as. Afinal, "é outro mundo" " Chega a presenciar mudança histórica, a qual reporta ciente da importância: a queda do Bando dos Quatro.

Seu livro é agradável não só pela narrativa, mas também pela riqueza das passagens reportadas, das fotos e das ilustrações e charges de sua inconfundível autoria.

\section{No outro lado do mundo: uma viagem para aprender, de João Alves Filho}

\footnotetext{
${ }^{4}$ HENFIL, 1980, p. 8.

${ }^{5}$ HENFIL, 1980, p. 17.
} 
O livro No outro lado do mundo: uma viagem para aprender de João Alves Filho, qualificado por seu prefacista, Joel Silveira, como "livro de repórter" traz características das narrativas de viagem, uma vez que João Alves Filho reportou a viagem de cerca de 60 dias à Ásia, visitando: o Japão, a Índia, a China, incluindo: Macau, Hong Kong e Taiwan, realizada na década de 1980 .

Esta obra de João Alves Filho, como informa o seu subtítulo é uma viagem de aprendizagem. $\mathrm{O}$ autor, eminente personalidade política do Estado de Sergipe, foi prefeito de Aracaju, governador daquele Estado e Ministro do Interior no governo de José Sarney, ocupações que deram as diretrizes e o apoio, inclusive diplomático, na empreita da viagem reportada. Tinha, assim, bem delineada a finalidade de sua viagem: aprender, ou seja, partiu com ciência de uma missão, "sabia exatamente para onde vai e, ali, o que deve ver" ${ }^{6}$. Tinha a missão de observar soluções adotadas para o desenvolvimento nacional, em especial na agricultura. Como o próprio autor afirmou:

... não se tratava de devaneio nem de exotismo; ao contrário, aquela viagem era acalentada por mim há muito tempo. Estava convencido de que as soluções para o desenvolvimento brasileiro, naturalmente múltiplas, necessariamente passariam pelo emprego racional da agricultura. ${ }^{7}$

Nessa obra, a China é reportada à luz "da nova política administrativa implantada a partir de 1978" $"$, dedicando 49 páginas exclusivamente à China continental, e discutindo: as semelhanças com o Brasil, os transportes públicos, a agricultura, a piscicultura, o comunismo, o poder político, a urbanização, o respeito à família e ao idoso, bem como, o futuro planejado - tudo evidenciando as marcantes transformações para a construção da China do século XXI. A obra dedica ainda algumas páginas às observações feitas a Hong Kong e a Macau, em especial, às transformações que ocorriam para a reunificação desses territórios à China continental e, ainda, sete páginas à Taiwan, comparando o progresso da Ilha de Formosa a um “Japão do século XXI”, ou seja, um Japão do próximo século, naquela época.

\section{Viajando pelos cinco continentes de José Cretella Júnior}

\footnotetext{
${ }^{6}$ Por Joel Silveira no prefácio da obra ALVES FILHO, 1988, p. 12.

${ }^{7}$ ALVES FILHO, 1988, p. 15.

${ }^{8}$ ALVES FILHO, 1988, p. 39.
} 
Dentre a extensa obra do sisudo professor de Direito, José Cretella Júnior, Viajando pelos cinco continentes destoa da rotina de sua literatura jurídica. Trata-se de um livro que quer contar ao leitor as viagens do advogado e intelectual brasileiro que correu o mundo não só em paragens corriqueiras, destinos comuns, mas também em outras paisagens completamente exóticas - na China visitou: Pequim, Cantão, Xangai, Macau e Hong Kong - que mereceram atenção, nota e comento sob uma narrativa objetiva e didática.

Igualmente, na sua obra, o leitor observa as transformações pelas quais a China passou. O que é narrado e descrito por Cretella Jr. evidencia a confrontação de mudanças. Mudanças que não se esgotam, continuam mudando. Como afirma o próprio autor "os romances, os contos e as poesias, líricas ou épicas, não envelhecem. Atravessam os séculos. Os livros de viagem... assim que editados começam a envelhecer".

O que é narrado pode transparecer pequenas transformações, mas importantes na construção da China moderna: indústria e comércio aquecidos, o sistema monetário próprio e independente, "um regime semi-capitalista, ditadura de um grupo, que se reúne todos os anos em Pequim".9.

\section{Conclusões}

Por meio da literatura em língua portuguesa aqui apontada, constrói-se uma história de transformações para a China. Com Wenceslau de Moraes, parte-se de uma China Imperial, em que seu governante está distante do povo, a miséria se alastra e o imperialismo das nações ocidentais massacra qualquer possibilidade de desenvolvimento humano ou econômico. Revoluções perpassam. Numa corrida armamentista, o Japão desponta como nação imperialista no Oriente. O Império Celeste cai. A República da China surge, estrutura-se, endurece e se transforma em popular. Neste ponto, a literatura em língua portuguesa nos reporta com entusiasmo o que está ocorrendo na China, vê-se já um desenvolvimento curioso, pelas narrativas de Lygia Fagundes Telles. Esse desenvolvimento, entretanto, seria mais tarde melhor explorado por Henfil, mesmo antes de a Coca-Cola ali chegar, reportando a "Libertação" e o cotidiano chinês após a Revolução Cultural. Pouco mais tarde, esse desenvolvimento comunista já é objeto de pesquisa para aplicação democrática por autoridade governamental brasileira

\footnotetext{
${ }^{9}$ CRETELLA JR., 2001, p. 285.
} 
como restou bem apontado pela narrativa de João Alves. E enfim aqui, Cretella Jr, nos revela uma China semi-capitalista, em que a modernidade já a integra totalmente às grandes paisagens cosmopolitas prontas para transformações que mudaram não só a China, mas o mundo.

Histórias, lendas, curiosidades são reportadas, evidenciado transformações de uma China devastada para uma China moderna, importante agente do concerto das nações, de grande projeção do equilíbrio mundial, destacado centro fornecedor e consumidor mundial basilar para a nova ordem econômica e política internacional.

\section{Referências Bibliográficas}

ALVES FILHO, João. No outro lado do mundo: uma viagem para aprender. Prefácio de Joel Silveira. Rio de Janeiro: Record, 1988.

CRETELLA JR., José. Viajando pelos cinco continentes. Rio de Janeiro: Forense Universitária, $2001,2^{\mathrm{a}}$ ed.

DUARTE, Constância Lima. Narrativas de viagem de Nísia Floresta. IN Via Atlântica. n. 2, jul. 1999.

EDITORA ABRIL, China e Japão no Século XIX (p. 141-168); A expansão imperialista na Ásia (p. 185-188); A partilha da China (p 188-189); A rebelião dos boxers (p 189-191); e O imperialismo norte-americano (p. 191-192). IN História das Civilizações. São Paulo: Editora Abril, 1975.

FREYRE, Gilberto. China tropical. Organizado por Edson Nery da Fonseca. Brasília: ed. UnB, 2003.

HENFIL, Henfil na China antes da coca-cola. São Paulo: Círculo do livro, 1980.

MORAES, Wenceslau de. Traços do extremo oriente. Lisboa: Parceria A. M. Pereira, 1971. . Traços do extremo oriente. Macau: COD, 2004. 
. Traços do extremo oriente. São Paulo: Sésamo, 2012.

. Paisagens da China e do Japão. Macau: COD, 2007.

SAID, Edward. Orientalismo: o oriente como invenção do ocidente. São Paulo: Companhia das Letras, 1996.

TELLES, Lygia Fagundes. Passaporte para a China: crônicas de viagem. São Paulo: Companhia das Letras, 2011. 